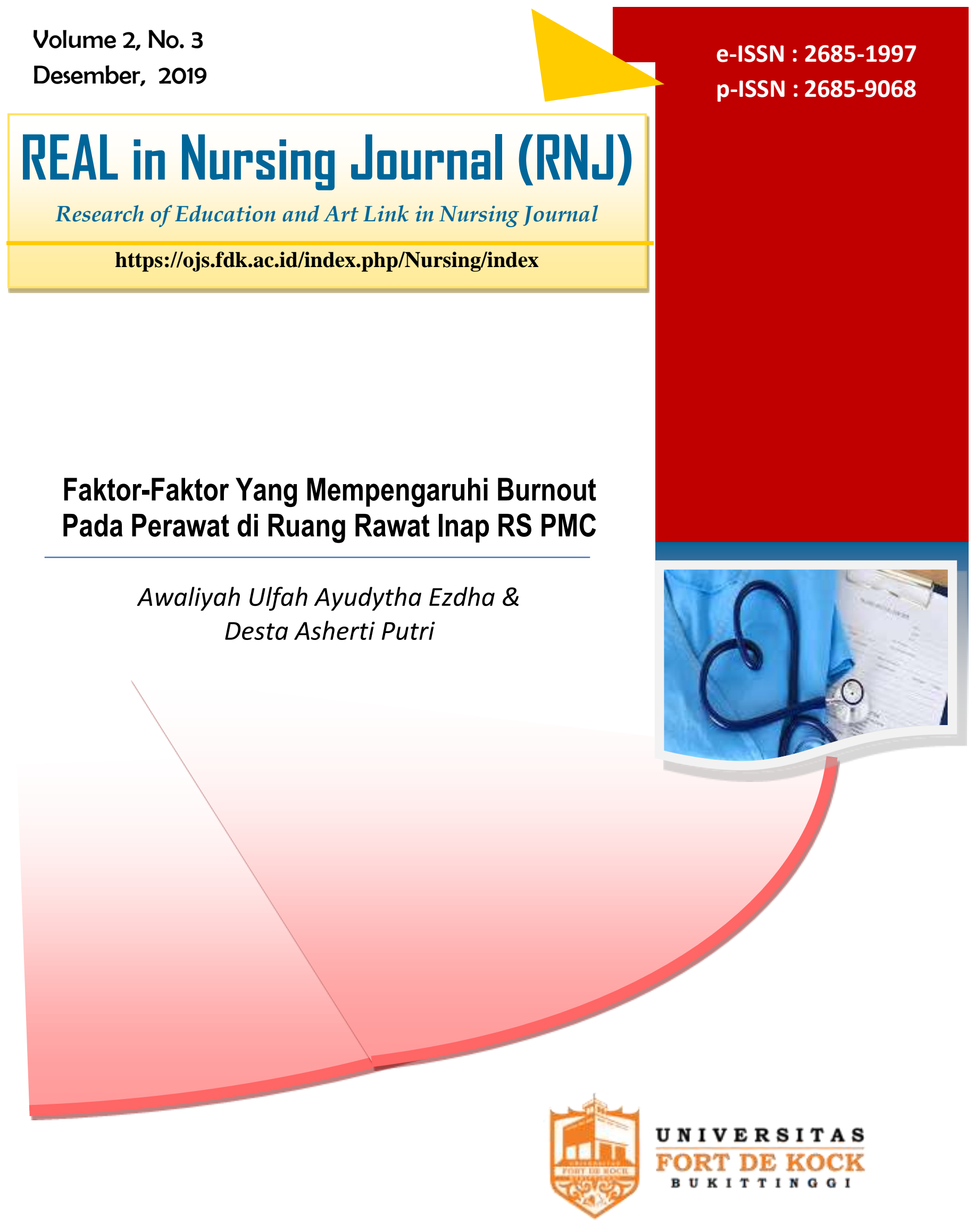

Faktor-Faktor Yang Mempengaruhi Burnout Pada Perawat di Ruang Rawat Inap RS PMC

Awaliyah Ulfah Ayudytha Ezdha \& Desta Asherti Putri

Program Studi Keperawatan dan Pendidikan Ners Universitas Fort de Kock Bukittinggi, Indonesia 


\title{
Faktor-Faktor Yang Mempengaruhi Burnout Pada Perawat di Ruang Rawat Inap RS PMC
}

\begin{tabular}{|c|}
\hline \hline REAL in \\
Nursing \\
Journal (RNJ) \\
https://ojs.fdk.ac.id/inde \\
x.php/Nursing/index \\
\hline
\end{tabular}

\section{Keywords: \\ Burnout, workload, Leadership style}

\section{Korespondensi:}

Awaliyah Ulfah Ayudytha

Ezdha

dhita_87@yahoo.com

STIKes Pekanbaru

Medical Center

\section{Awaliyah Ulfah Ayudytha Ezdha \& Desta Asherti Putri}

\begin{abstract}
Burnout is a prolonged response related to stressors that continue to occur in the workplace where the result is a combination of workers and jobs. Nurse fatigue occurs when nurses work more than $80 \%$ of their work time. The purpose of this study was to determine the factors that influence burnout in nurses in the inpatient room of Pekanbaru Medical Center hospital in 2019. This research method was descriptive correlation with cross sectional approach done to 35 respondents. Sampling technique using total sampling method. The analysis used is univariate analysis and bivariate analysis using Chi-square test. The results showed that there was a significant relationship between workload and burnout $(p=0.024)$ and there was a significant relationship between leadership style and burnout ( $p$ $=0.027$ ). Based on the results of these studies, the researchers recommend that the management of Pekanbaru Medical Center Hospital pay more attention to the level of burnout nurses because the performance of nurses plays an important role in patient care.
\end{abstract}

\begin{abstract}
ABSTRAK
Burnout merupakan respon yang berkepanjangan terkait faktor penyebab stres yang terus-menerus terjadi tempat kerja di mana hasilnya merupakan perpaduan antara pekerja dan pekerjaannya. Kelelahan perawat terjadi bila perawat bekerja lebih dari $80 \%$ dari waktu kerja mereka. Tujuan dari penelitian ini adalah untuk mengetahui faktor-faktor yang mempengaruhi burnout pada perawat diruang rawat inap rumah sakit Pekanbaru Medical Center tahun 2019. Metode penelitian ini adalah deskriptif korelasi dengan pendekatan cross sectional yang dilakukan terhadap 35 responden. Tehnik pengambilan sampel menggunakan cara total sampling. Analisa yang digunakan adalah analisa univariat dan analisa bivariat dengan menggunakan uji Chi-square. Hasil penelitian menunjukkan ada hubungan yang signifikan antara beban kerja dengan burnout $(p=0,024)$ dan ada hubungan yang signifikan antara gaya kepemimpinan dengan burnout $(p=0,027)$. Berdasarkan hasil penelitian tersebut, maka peneliti merekomendasikan agar pihak manajemen Rumah Sakit Pekanbaru Medical Center lebih memperhatikan tingkat burnout perawat karena kinerja perawat memegang peranan penting dalam perawatan pasien.
\end{abstract}

Kata Kunci : Burnout , Beban kerja, Gaya kepemimpinan 


\section{PENDAHULUAN}

Rumah sakit merupakan penyedia layanan kesehatan yang memiliki karakteristik berbeda dengan organisasi lainnya. Karakteristik tersebut lah yang dapat mempengaruhi suatu organisasi dalam rumah sakit. Perawat adalah salah satu sumberdaya manusia di rumah sakit yang jumlahnya mendominasi tenaga kesehatan secara menyeluruh dan penjalin hubungan yang lama dengan pasien serta keluarganya. Perawat merupakan ujung tombak baik tidaknya pelayanan kesehatan yang di berikan kepada pasien. Hal ini disebabkan karena jumlahnya yang dominan (50-60\% dari seluruh tenaga yang ada), dan bertugas merawat dan menjaga pasien selama 24 jam sehari. Pelayanan yang baik dengan demikian tidak terlepas dari adanya komitmen dari perawat untuk memberikan pelayanan yang baik kepada pasien ( Runtu, 2009).

Pekerjaan perawat yang menciptakan tuntutan kerja yang tinggi,seperti pekerjaan yang rutin, jadwal kerja yang ketat,tanggung jawab atas keselamatan dan kesehatan diri sendiri dan orang lain, serta dituntut untuk mampu bekerja dalam tim. Kompleksnya tuntutan pekerjaan dan tanggung jawab perawat menyebabkan profesi perawat rentan mengalami burnout (Lailani, 2012).

Burnout merupakan masalah kesehatan kerja dan produktivitas kerja dengan prevalensi kejadian yang terus meningkat sehingga memerlukan perhatian serius dari para pemangku kepentingan. Maslach dan Jackson (dalam Guilermoet al, 2015) menyebutkan burnout perawat adalah kondisi yang menggambarkan respon terhadap stres kronis berhubungan dengan pekerjaan.

Kelelahan dapat disebabkan oleh beberapa faktor antara lain rotasi shift kerja, faktor individu (kesehatan/ penyakit, jenis kelamin, umur, pendidikan, beban kerja, masa kerja) dan faktor lingkungan fisik (kebisingan, penerangan, suhu dan tekanan panas, vibrasi dan ventilasi). Kelelahan kerja di rumah sakit antara lain kelelahan yang disebabkan faktor fisik seperti suhu, penerangan, mikroorganisme, zatkimia, kebisingan dan cyrcardian rhythm (terutama pada perawat shift malam), sedangkan kelelahan non fisik disebabkan oleh faktor psikososial baik di tempat kerja maupun di rumah atau masyarakat sekeliling (Setyawati, 2011).

Dari studi pendahuluan yang dilakukan peneliti di Rumah Sakit Pekanbaru Medical Center pada 17 Desember 2018 melalui wawancara dengan perawat pelaksana dan kepala ruangan didapatkan bahwa sebagian perawat yang bekerja di Rumah Sakit Pekanbaru Medical Center pendidikan terakhirnya adalah profesi ners dan masih ada sebagian perawat yang pendidikan terakhirnya D3. Perawat mengatakan stres karena kadang harus menghadapi pasiean atau keluarga pasien yang sifatnya berbeda-beda dan kadang sedikit cerewet. Dari hasil yang dilihat oleh peneliti saat studi pendahuluan sebagian perawat tampak tidak bersemangat saat bekerja, perawat yang hanya duduk-duduk bermain handphone, dan ada juga perawat yang malas dan lama datang keruangan pasien saat dipanggil oleh keluarga pasien.Akibat dari perawat yang merasa jenuh dan bosan bekerja dapat menyebabkan perawat merasa stres dan keinginan bekerja semakin menurun.

Faktor faktor seperti faktor individu (Jenis Kelamin, Umur, Tingkat Pendidikan, Masa Kerja, dan Status), Faktor Lingkungan (Beban Kerja dan Rekan Kerja) serta faktor Organisasi (Gaya Kepemimpinan dan Reward) mungkin dapat mempengaruhi terjadinya burnout pada 
perawat. Melihat fenomena yang telah dibahas sebelumnya pada latar belakang di atas, maka peneliti tertarik untuk melakukan penelitian dengan judul "Faktor-faktor yang mempengaruhi burnout pada perawat diruang rawat inap Rumah Sakit Pekanbaru Medical Center Tahun 2019".

\section{METODOLOGI PENELITIAN}

Jenis penelitian ini adalah deskriptif korelasi dengan menggunakan rancangan Cross Sectional Study karena untuk mencari hubungan antara variabel independen dan dependen hanya sesaat atau satu kali saja dalam satu kali waktu (Setiadi, 2013). Variabel independen pada penelitian ini adalah faktorfaktor yang mempengaruhi burnout pada perawat (faktor individu, faktor lingkungan, dan faktor organisasi), variabel dependen adalah adalah burnout. Penelitian ini dilaksanakan di Rumah Sakit Pekanbaru Medical Center, pada bulan April 2019. Populasi dalam penelitian ini adalah seluruh perawat yang ada diruang rawat inap Rumah Sakit Pekanbaru Medical Center. Teknik pengambilan sampel dilakukan secara total sampling, dan didapatkan sebanyak 35 sampel.

Intrument penelitian yang di gunakan pada penelitian ini adalah kuesioner yang dibuat oleh peneliti sendiri yang telah di lakukan uji validitas. Pengumpulan data primer dengan cara menyebarkan melalui serangkaian pengumpulan data dengan penyebaran kuesioner melakukan kepada responden sebanyak 35 responden, Analisis data di lakukan secara univariat dan bivariat menggunkan uji pearson chi-square.

\section{HASIL PENELITIAN}

Penelitian dilakukan di Rumah Sakit Pekanbaru Medical Center dari bulan november 2018 hingga Juni 2019. Responden yang diambil berjumlah 35 orang dan menjawab secara lengkap, yang digambarkan melalui tabel dibawah ini:

Tabel 4.11

Hubungan faktor individu dengan burnout pada perawat rawat inap di Rumah Sakit Pekanbaru Medical Center

\begin{tabular}{|c|c|c|c|c|c|c|c|c|}
\hline & \multirow{3}{*}{ Faktor Individu } & \multicolumn{4}{|c|}{ Variabel Burnout } & \multirow{2}{*}{\multicolumn{2}{|c|}{ Jumlah }} & \multirow{3}{*}{$P$ value } \\
\hline & & \multicolumn{2}{|c|}{$\begin{array}{l}\text { Mengalami } \\
\text { burnout }\end{array}$} & \multicolumn{2}{|c|}{$\begin{array}{c}\text { Tidak mengalami } \\
\text { burnout }\end{array}$} & & & \\
\hline & & $\mathrm{N}$ & $\%$ & $\mathrm{~N}$ & $\%$ & $\mathrm{~N}$ & $\%$ & \\
\hline 1. & Jenis kelamin & & & & & & & \\
\hline & - Perempuan & 17 & $60,7 \%$ & 11 & $19,3 \%$ & 28 & $100 \%$ & 0680 \\
\hline & - Laki-laki & 5 & $71,4 \%$ & 2 & $28,6 \%$ & 7 & $100 \%$ & 0,089 \\
\hline 2 & Umur & & & & & & & \\
\hline & - 20-30 tahun & 19 & $59,4 \%$ & 13 & $40,6 \%$ & 32 & $100 \%$ & 0 279 \\
\hline & - $\quad 31-40$ tahun & 3 & $100 \%$ & 0 & $0 \%$ & 3 & $100 \%$ & $0, \angle 19$ \\
\hline 3 & Pendidikan & & & & & & & \\
\hline & - DIII Keperawatan & 17 & $70,8 \%$ & 7 & $29,2 \%$ & 24 & $100 \%$ & 0258 \\
\hline & - Ners & 5 & $45,5 \%$ & 6 & $54,5 \%$ & 11 & $100 \%$ & 0,200 \\
\hline 4 & Masa kerja & & & & & & & \\
\hline & $-\quad<3$ tahun & 5 & $71,4 \%$ & 2 & $28,6 \%$ & 7 & $100 \%$ & 0689 \\
\hline & $->3$ tahun & 17 & $60,7 \%$ & 11 & $39,3 \%$ & 28 & $100 \%$ & 0,009 \\
\hline 5 & Status & & & & & & & \\
\hline & - Menikah & 9 & $64,3 \%$ & 5 & $35,7 \%$ & 14 & $100 \%$ & 1000 \\
\hline & - Belum menikah & 13 & $61,9 \%$ & 8 & $38,1 \%$ & 21 & $100 \%$ & 1,000 \\
\hline
\end{tabular}


Hasil uji statistik diperoleh nilai $P$ value $=$ 0,689 maka dapat disimpulkan $p$ value > nilaia $(0,05)$ hal ini menunjukkan tidak ada hubungan antara jenis kelamin dengan burnout pada perawat. Hasil uji statistik diperoleh nilai $P$ value $=0,279$ maka dapat disimpulkan $p$ value $>$ nilai $a(0,05)$ hal ini menunjukkan tidak ada hubungan antara umur dengan burnout pada perawat. Hasil uji statistik diperoleh nilai $P$ value $=0,258$ maka dapat disimpulkan $p$ value < nilai $a(0,05)$ hal ini menunjukkan tidak ada hubungan antara

Tabel 4.15

Hubungan faktor lingkungan dengan burnout pada perawat rawat inap

\begin{tabular}{|c|c|c|c|c|c|c|c|c|}
\hline \multicolumn{9}{|c|}{ Tabel 4.15} \\
\hline & \multirow{3}{*}{$\begin{array}{c}\text { Faktor } \\
\text { Lingkungan }\end{array}$} & \multicolumn{4}{|c|}{ Variabel Burnout } & \multirow{2}{*}{\multicolumn{2}{|c|}{ Jumlah }} & \multirow{3}{*}{$P$ value } \\
\hline & & \multicolumn{2}{|c|}{$\begin{array}{l}\text { Mengalami } \\
\text { burnout }\end{array}$} & \multicolumn{2}{|c|}{$\begin{array}{c}\text { Tidak mengalami } \\
\text { burnout }\end{array}$} & & & \\
\hline & & $\mathrm{N}$ & $\%$ & $\mathrm{~N}$ & $\%$ & $\mathrm{~N}$ & $\%$ & \\
\hline 1. & Beban kerja & & & & & & & \multirow{3}{*}{0,024} \\
\hline & - Berat & 18 & $78,3 \%$ & 5 & $21,7 \%$ & 23 & $100 \%$ & \\
\hline & - Ringan & 4 & $33,3 \%$ & 8 & $66,7 \%$ & 12 & $100 \%$ & \\
\hline \multirow[t]{3}{*}{2} & Rekan kerja & & & & & & & \\
\hline & - Baik & 13 & $76,5 \%$ & 4 & $23,5 \%$ & 17 & $100 \%$ & \\
\hline & - Kurang baik & 9 & $50 \%$ & 9 & $50 \%$ & 18 & $100 \%$ & 0,204 \\
\hline
\end{tabular}

Hasil uji statistik diperoleh nilai $P$ value $=0,024$ maka dapat disimpulkan $p$ value $<$ nilai a $(0,05)$ hal ini menunjukkan ada hubungan antara beban kerja dengan burnout pada perawat. pendidikan terakhir dengan burnout pada perawat. Hasil uji statistik diperoleh nilai $P$ value $=0,689$ maka dapat disimpulkan $p$ value > nilai a $(0,05)$ hal ini menunjukkan tidak ada hubungan antara masa kerja dengan burnout pada perawat. Hasil uji statistik diperoleh nilai $P$ value $=1,000$ maka dapat disimpulkan $p$ value > nilai $a(0,05)$ hal ini menunjukkan tidak ada hubungan antara status perkawinan dengan burnout pada perawat.

Tabel 4.17

Hubungan faktor organisasi dengan burnout pada perawat rawat inap

\begin{tabular}{|c|c|c|c|c|c|c|c|c|}
\hline & \multirow{3}{*}{ Faktor Organisasi } & \multicolumn{4}{|c|}{ Variabel Burnout } & \multirow{2}{*}{\multicolumn{2}{|c|}{ Jumlah }} & \multirow{3}{*}{$P$ value } \\
\hline & & \multicolumn{2}{|c|}{$\begin{array}{l}\text { Mengalami } \\
\text { burnout }\end{array}$} & \multicolumn{2}{|c|}{$\begin{array}{c}\text { Tidak mengalami } \\
\text { burnout }\end{array}$} & & & \\
\hline & & $\mathrm{N}$ & $\%$ & $\mathrm{~N}$ & $\%$ & $\mathrm{~N}$ & $\%$ & \\
\hline 1. & Gaya kepemimpinan & & & & & & & \\
\hline & - Otoriter & 12 & $50 \%$ & 12 & $50 \%$ & 24 & $100 \%$ & \\
\hline & - Demokratis & 10 & $90,9 \%$ & 1 & $9,1 \%$ & 11 & $100 \%$ & 0,027 \\
\hline 2 & Pemberian reward & & & & & & & \\
\hline & - Ada & 19 & $73,1 \%$ & 7 & $26,9 \%$ & 26 & $100 \%$ & 0050 \\
\hline & - $\quad$ Tidak ada & 3 & $33,3 \%$ & 6 & $66,7 \%$ & 9 & $100 \%$ & 0,050 \\
\hline
\end{tabular}

Hasil uji statistik diperoleh nilai $P$ value $=0,027$ maka dapat disimpulkan $p$ value $<$ nilai $a$
Hasil uji statistik diperoleh nilai $P$ value $=0,204$ maka dapat disimpulkan $p$ value $>$ nilai $a(0,05)$ hal ini menunjukkan tidak ada hubungan antara rekan kerja dengan burnout pada perawat. 
pada perawat. Hasil uji statistik diperoleh nilai $P$ value $=0,050$ maka dapat disimpulkan $p$ value $=$ nilai $\alpha(0,05)$ hal ini menunjukkan tidak ada hubungan antara pemberian reward dengan burnout pada perawat.

\section{PEMBAHASAN}

Hubungan faktor individu dengan burnout pada perawat diruang rawat inap Rumah Sakit Pekanbaru Medical Center

Berdasarkan dari hasil uji Chi-square yang dilihat dari nilai fisher exact diperoleh nilai $p=$ 0,279 , maka dapat disimpulkan bahwa tidak terdapat hubungan antara umur dengan burnout pada peraat diruang rawat inap Rumah sakit pekanbaru medical center.

Penelitian ini sejalan dengan penelitian yang dilakukan oleh Fadly (2016) menyatakan bahwa sebanyak 62 perawat $(49,6 \%)$ yang berusia 20-30 tahun dengan nilai $p=0,426$ menunjukkan bahwa tidak terdapat hubungan antara umur dengan burnout. Tidak adanya hubungan umur perawat dengan burnout dalam penelitian ini dikarenakan beberapa hal antara lain; komposisi umur perawat di setiap ruangan lebih banyak berusia kurang dari 40 tahun. Dengan hal ini maka peneliti berasumsi bahwa tidak adanya hubungan umur dengan burnout pada penelitian ini disebabkan karena tidak meratanya sebaran usia responden yang kurang merata, dimana responden didominasi oleh kelompok dewasa muda dan tidak hanya umur yang dapat mempengaruhi burnout pada perawat tetapi ada faktor lain yang dapat menyebabkan burnout pada perawat.

Berdasarkan hasil uji chi- square yang dilihat dari nilai fisher exact diperileh nilai $p=0,279$ yang artinya tidak ada hubungan antara jenis kelamin dengan burnout pada perawat diruang rawat inap Rumah Sakit Pekanbaru Medical Center. Penelitian ini sama dengan penelitian yang dilakukan oleh Perwitasari (2015) menunjukkan nilai $p=0,572$ yang disimpulakan tidak ada hubungan antara jenis kelamin dengan burnout. Tidak adanya hubungan ini memiliki arti bahwa banyak faktor yang mempengaruhi kelelahan dan faktor jenis kelamin bukan merupakan faktor yang berhubungan secara langsung dengan terjadinya kelelahan. Yusuf dan Asdar (2018), mengatakan bahwa wanita akan lebih cenderung mengalami burnout dibanding lakilaki, karena perawat wanita kemungkinan mangalami konflik antara mengurus keluarga dan menolong pasien secara profesionel yang sudah menjadi tanggung jawabnya. Dengan hal peneliti berasumsi bahwa tidak adanya hubungan yang signifikan kemungkinan disebabkan karena kurangnya pemerataan jumlah perawat berdasarkan jenis kelamin. Namun, hasil lain dari penelitian ini menunjukkan bahwa perempuan cenderung mengalami tingkatan burnout syndrome yang lebih tinggi dari laki-laki. Jenis kelamin wanita lebih cenderung rentan mengalami burnout, hal ini disebabkan wanita memiliki tanggung jawab lebih, dimana wanita harus dituntut profesional terhadap pasien dan juga harus mengurus keluarga.

Dari hasil uji chi-quare yang dilakukan diperoleh nilai $p=0,258$ yang disimpulakan bahwa tidak ada hubungan antara pendidikan dengan burnout pada perawat diruang rawat inap Rumah Sakit Pekanbaru Medical Center. Tingkat pendidikan responden didominasi oleh tingkat pendidikan DIII Keperawatan yaitu sebanyak 52 orang $(98,1 \%)$ dan hanya 1 orang $(1,9 \%)$ dengan tingkat pendidikan $\mathrm{S1}$ Keperawatan. Hal ini berbanding terbalik dengan yang dikatakan oleh Mizmir (2010) bahwah pekerja yang berpendidikan dibawah sarjana akan mengalami resiko burnout lebih rendah. Namun berdasarkan hasil tabulasi 
silang yang dilakukan peneliti didapatkan bahwa sebanyak 17 responden $(70,8 \%)$ yang berpendidikan DIII lebih banyak mengalami burnout dibandingkan dengan responden yang berpendidikan Ners hanya 5 responden yang mengalami burnout. Berdasarkan hal itu maka peneliti berasumsi bahwa tidak adanya hubungan antara tingkat pendidikan dengan burnout disebabkan karena perawat diruang rawat inap didominasi oleh perawat yang berpendidikan DIII sehingga sulit untuk membandingkan dengan perawat yang berpendidikan Ners.

Dari hasil uji chi-square didapatkan nilai $p=$ 0,689 yang didapat disimpulkan bahwa tidak ada hubungan antara masa kerja dengan burnout pada perawat diruang rawat inap Rumah Sakit Pekanbaru Medical Center. Penelitian ini berbeda dengan penelitian sebelumnya yang dilakukan oleh Sari (2015) diperoleh nilai $p=0,000$ yang disimpulkan ada hubungan antara masa kerja dengan burnout pada perawat, pada penelitian ini perawat yang bekerja > 5 tahun hanya 5 orang yang mengalamiburnout. Dengan hal ini maka peneliti berasumsi tidak adanya hubungan antara masa kerja dengan burnout pada perawat dikarenakan pekerjaan yang monoton juga dapat menyebabkan perawat dengan masa kerja $<3$ atau $>3$ tahun cenderung mengalami burnout, Walaupun dengan masa kerja yang lama seorang perawat mendapatkan pengalaman kerja yang banyak, namun pola pekerjaan perawat yang monoton dan bersifat human service justru menimbulkan kelelahan fisik, emosi dan psikologi yang mengarah pada burnout.

Dari hasil uji chi-square didapatkan nilai $p=$ 1,000 maka dapat disimpulkan tidak ada hubungan antara status perkawinan dengan burnout pada perawat diruang rawat inap
Rumah Sakit Pekanbaru Medical Center. Namun penelitian ini sejalan dengan yang dikatakan oleh Mizmir (2010) Pekerja yang berstatus lajang lebih mengalami burnout dari pada pekerja yang berstatus menikah. Jika dibandingkan dengan individu yang mempunyai anak dan individu yang tidak mempunyai anak maka individu yang memiliki anak cenderung memiliki tingkat burnout yang lebih rendah karena seseornag yang telah menikah umumnya berusia lebih tua, lebih stabil, dan lebih matang secara psikologis, Keterlibatan keluarga dan anak dapat mempersiapkan mental seseorang dalam menghadapi masalah dan konflik emosional, kasih sayang dan dukungan keluarga dapat membantu seseorng dalam menyelesaikan masalah emosionalnya serta seseorang yang sudah menikah atau yang sudah lebih dewasa memiliki pandangan realistis.

\section{Hubungan faktor lingkungan dengan burnout pada perawat diruang rawat inap Rumah Sakit Pekanbaru Medical Center}

Dari hasil uji chi-square dilihat dari nilai fisher exact nilai $p=0,024$ yang disimpulkan bahwa ada hubungan antara beban kerja dengan burnout pada Perawat diruang rawat inap Rumah Sakit Pekanbaru Medical Center. Dengan ini peneliti berasumsi ada hubungan antara beban kerja dengan burnout di sebabkan karena sebagian besar di Rumah Sakit Pekanbaru Medical Center memiliki beban kerja yang berat, sehingga membuat sebagian perawat mengalami burnout, terlihat dari sebagian besar responden mengatakan merasa terbebani karena beban kerja yang terlalu tinggi dan responden mengatakan tingginya beban kerja yang ada diruangan membuat mereka merasa terganggu dalam melakukan tindakan keperawatan dan kurang fokus untuk melakukan asuhan keperawatan 
pada pasien. Beban kerja yang tinggi akan menyebabkan perawat mengalami burnout, rumah sakit harus bisa menyesuaikan jumlah tenaga perawat yang dibutuh kan terhadap beban kerja yang di hadapi, tanggung jawab dan tuntutan pekerjaan yang banyak dapat berpotensi menjadi stresor bagi perawat. Stresor yang terjadi secara terus menerus dan tidak mampu diadaptasi oleh individu akan menimbulkan beberapa gejala yang disebut dengan burnout.

Dari hasil uji chi-square diperoleh nilai $p=$ 0,204 yang disimpulkan bahwa tidak ada hubungan antara rekan kerja dengan burnout pada perawat diruang rawat inap Rumah Sakit Pekanbaru Medical Center. Dari hasil penelitian yang dilakukan oleh Asrtiani (2015) tentang hubungan dukungan sosial rekan kerja diketahui nilai korelasi ( $r x y$ ) sebesar $-0,577 ; p=$ $0,000(p<0,01)$ yang artinya ada hubungan negatif yang sangat signifikan antara dukungan sosial dengan burnout pada perawat. Dengan ini peneliti berasumsi bahwa tidak ada hubungan antara rekan kerja dengan burnout disebabkan karena kemungkinan dukungan sosial antar rekan kerja bukan salah satu faktor langsung yangdapat menyebabkan terjadinya burnout.

\section{Hubungan faktor organisasi dengan burnout pada perawat diruang rawat inap Rumah Sakit Pekanbaru Medical Center}

Dari hasil uji chi-square didapatkan nilai fisher exact yaitu $p=0,027$ yang disimpulkan bahwa ada hubungan gaya kepemimpinan dengan bunrout pada perawat diruang rawat inap Rumah Sakit Pekanbaru Medical Center. Gaya kepemimpinan kepala ruang yang buruk menjadi beban tambahan seorang perawat pelaksana dalam menjalankan tugasnya, jika seorang perawat tersebut tidak memiliki mekanisme koping yang baik maka akan menimbulkan stress kerja yang berkepanjangan dan jika tidak teratasi akan menjadi burnout. Dengan ini peneliti berasumsi bahwa gaya kepemimpinan yang digunakan kepala ruangan harus berdasarkan pada situasi dan kondisi serta kemampuan dari seluruh anggota karena gaya kepemimpinan yang tepat di implementasikan oleh kepala ruangan sangat berpengaruh terhadap kinerja perawat di ruangan, kepala ruangan yang kurang peduli terhadap beban kerja dan keluhan perawat akan menjadi pemicu terjadinya burnout pada perawat. Dari dua gaya kepemimpinan tersebut tidak ada yang salah, namun pada penelitian ini yang menyebabkan gaya kepemimpinan berhubungan dengan burnout pada perawat dirumah sakit pekanbaru medical center karena ketidaksiapan individu perawat itu sendiri menerima perintah dari atasannya atau mekanisme koping yang kurang baik lah yang membuat perawat mengalami burnout.

Dari hasil uji chi-square diperoleh nilai fisher exact yaitu $p=0,050$ dapat disimpulkan tidak ada hubungan antara pemberian reward dengan burnout pada perawat diruang rawat inap Rumah Sakit Pekanbaru Medical Center. Penelitian ini belum bisa dibandingkan dengan penelitian lain karna keterbatasan peneliti untuk mendapatkan referensi lebih banyak yang membahas tentang hubungan reward terhadap burnout perawat, peneliti berasumsi bahwa pemberian reward tidak berhubungan karena ada faktor lain yang dapat menyebabkan burnout pada perawat bukan saja karena ada atau tidaknya pemberian reward dirumah sakit. Dengan ini peneliti juga berasumsi dengan mendapatkan reward yang layak secara materil ataupun dukungan sosial atas pencepaian kinerja nya perawat akan merasa dihargai sehingga akan menurunkan terjadinya burnout. 
Kurniawati (2013) yang mengatakan reward dapat berupa keuangan, sosial dan konsisten dengan harapan seseorang, ketika seseorang merasa diabaikan karena tidak dihargai secara material dan dukungan sosial, dia akan kehilangan nilai-nilai dalam mencapai tujuan dari pekerjaannya. Hal ini akan menunjukkan bahwa penurunan reward akan berpeluang munculnya kejadian burnout.

\section{KESIMPULAN}

Berdasarkan hasil penelitian tentang faktorfaktor yang mempengaruhi burnout pada perawat diruang rawat inap Rumah Sakit Pekanbaru Medical Center dapat ditarik kesimpulan dari hasil distribusi frekuensi berdasarkan faktor individu responden di Rumah Sakit Pekanbaru Medical Center didapatkan hasil sebagain besar responden memiliki umur 20-30 tahun sebanyak 32 responden $(91,4 \%)$, berjenis kelamin perempuan sebanyak 28 responden $(80 \%)$, berpendidikan DIII Keperawatan sebanyak 24 responden $(68,6 \%)$, bekerja selama $>3$ tahun sebanyak 28 responden (80\%),dan berstatus belum menikah sebanyak 21 responden $(60 \%)$.

Ada hubungan antara beban kerja dengan burnout pada perawat diruang rawat inap Rumah Sakit Pekanbaru Medical Center dengan berdasarkan hasil analisa data didapatkan $p=0,024$. Ada hubungan yang signifikan antara gaya kepemimpinan dengan burnout pada perawat diruang rawat inap Rumah Sakit Pekanbaru Medical Center dengan berdasarkan hasil analisa data didapatkan $p=0,027$.

Pada penelitian ini saran yang di dapat di berikan kepada Rumah sakit agar senantiasa memperhatikan kinerja perawat sehingga tidak ada perawat yang mengalami burnout yang dapat menyebabkan penurunan kualitas pelayanan di Rumah Sakit Pekanbaru Medical Center. Bagi perawat yang bertugas di RS Pekanbaru Medical Center untuk lebih mengetahui tentang tanda dan gejala serta faktor yang mempengaruhi terjadinya burnout sehingga tercipta lingkungan kerja dan kinerja yang lebih baik.

\section{UCAPAN TERIMA KASIH}

Ucapan terima kasih yang tak terhingga kami sampaikan kepada Ketua STIKes Pekanbaru Medical Center (PMC) Pekanbaru dan Direktur Rumah Sakit PMC serta Manajemen RS yang telah memberikan ijin kepada peneliti. Selain itu kepada perawat yang ikut serta dalam penelitian ini sehingga penelitian ini dapat terlaksana dan mendapatkan data yang mendukung hasil penelitian.

\section{DAFTAR PUSTAKA}

Astriana, dkk. 2014. Hubungan Pendidikan, Masa Kerja Dan Beban Kerja dengan Keselamatan Pasien RSUD Haji Makassar. Artikel. Manajemen Rumah Sakit Fakultas Kesehatan Masyarakat Universitas Hasanuddin

Dita Perwitasari, Abdul Rohim Tualeka. 2014. Faktor yang berhubungan dengan kelelahan kerja subjektif pada perawat di RSUD DR. MOHAMAD SOEWANDHIE SURABAYA. The Indonesian Journal of Occupational Safety, Health and Environment, Vol. 1, No. 1 Jan-April 2014: 15-23

Iwan M. Ramdan, Oktavian Nursan Fadly. 2016. Analisis Faktor yang Berhubungan dengan Burnout pada Perawat Kesehatan Jiwa. Fakultas Kesehatan Masyarakat, Universitas Mulawarman

Ni Luh Putu Dian Yunita Sari. 2015. Hubungan beban kerja, faktor demografi, locus of control dan harga diri terhadap burnout syndrome pada perawat pelaksana IRD 
REAL in Nursing Journal (RNJ), Vol. 2, No. 3 Ezdha, AUA \& Putri, DA. (2019). RNJ. 2(3) : 144-152

RSUP SANGLAH.NersJournal : ISSN: 2303-1298

Runtu, Delon. Y. N \&Widyarini, Nilam M.M. 2009. Iklim Organisasi, Stres Kerja, Dan Kepuasan Kerja Pada Perawat. Jurnal Psikologi Volume 2,No. 2, Juni 2009

Sari, Ikakasmita. 2015. Faktor - faktor yang Berhubugan dengan Burnout perawat di RSUD Haji Makassar. Makassar :IImu kesehatan Uin Alauddin Makassar
Setiadi. 2013. Konsep dan Praktis Penulisan Riset Keperawatan. Yogyakarta :Graha IImu

Yusuf, Eka fadly \& Asdar Muhammad. 2018. Manajemen Sumber Daya Manusia ; Burnout dalam Tinjauan Studi Keperawatan. Makassar :Nas Media Pustaka 